\title{
Preliminary Study of Environmental Impact Related to E-commerce Activities in Thailand
}

\author{
Thanarak Prasertwit* and Kanchana Kanchanasuntorn \\ School of Engineering, University of the Thai Chamber of commerce, Bangkok, Thailand
}

\begin{abstract}
E-commerce is being a big growth in global commercial because of its ease and no need for the real store. The value of E-commerce in Thailand is predicted to be 4.67 trillion Baht in 2021 . However, Thailand has been facing several environmental problems such as waste, congestion and pollution. Therefore, the objective of this paper is to acknowledge the basics of environmental impact by using intensive review and in-depth interview from experts in E-commerce to find out the Ecommerce processes and activities in Thailand and also analyzing the activities that impact on the environment. The study found that when the value of E-commerce in Thailand has been increased which means the more frequently purchase of products, the more waste is produced because of individual packaging. Then analyze E-commerce activities from E-commerce partner that impact on environment and found the E-commerce processes that impact on the environment which are firstly, the process of repacking produces waste from additional packaging, secondly, the process of customer purchasing from searching for products to placing an order has impact on environment in terms of energy use and device charging. Finally, the delivery process also has impact on environment because of the energy used and pollution.
\end{abstract}

\section{Research background}

Since the fast growth of E-commerce business, trend of E-commerce sales is predicted to get a bigger share of offline retail every year. E-commerce makes life convenient, the customer can easily access the product, make an order from anywhere and delivery quickly direct to the customer's front door. Sustainability of implementing E-commerce can be seen in terms of driving economic, job creation and value creation. On the other hand, sustainability in terms of environment for E-commerce implementation is less concerned. Pollution from mass of traffic, waste from individual packaging and energy consumption are causing impacts to the environment. Even, many countries have done research and analysis about an environmental impact from E-commerce activities, Thailand may have some different processes and specific behavior which leads to environmental impact, so it is vital to intensely analyze E-commerce activities in the context of Thailand. Therefore, the objectives of this paper are firstly, to study the e-commerce process in Thailand secondly, to study trends of environmental impact from E-commerce activities and thirdly, to find out the factor and intensive analyze environmental impact from each E-commerce activity.

\section{Research methodology}

The aims of this paper are to explore the current situation of E-commerce in Thailand, find out the effect factor and intensively analyze the environmental impact from each E-commerce activity. An intensively review of academic literature is used to acknowledge the basics of the environmental impact of the E-commerce process from various countries, then in-depth interviews from experts in E-commerce in Thailand to find out and gather the Ecommerce process all along the chain. So far, the paper is done on synthesis and analysis of E-commerce activities to find the environmental impact factor and summarized environmental impact that occur in each Ecommerce activity in the context of Thailand. The main keywords are E-commerce, environment and Ecommerce. The research database is used from web site search engines such as science direct and google scholar. The research methodology diagram has been shown in Figure 1.

\footnotetext{
* Corresponding author: thanarak_p@hotmail.com
} 


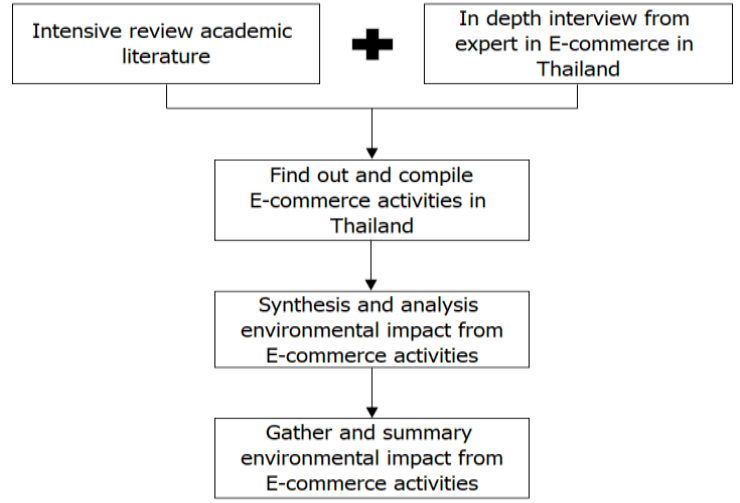

Fig. 1. Research methodology process diagram

\section{Research result}

The results of this study are E-commerce trend in Thailand, E-commerce process in Thailand, environmental impact from E-commerce process in Thailand, E-commerce environmental impact study in other countries, an analysis of E-commerce process and activities on the environmental impact in Thailand and conclusion.

\subsection{E-commerce trend in Thailand}

In the world of competitiveness, the business has to move fast to serve their customer needs. One of the most popular solutions that the business implements is selling the product via E-commerce. The ease of using Ecommerce helps the customer to buy the product online more conveniently in just one click and as a result, sales of E-commerce over the world is growing continually and getting a bigger share of offline retail every year.

E-commerce enables the customer to easily access the product from anywhere and receive the product directly to the customer's front door. Many services have been set up to support the activities such as special packaging in order to protect the product as an individual parcel sends direct to a customer's house, logistics providers are set up to support a growth of last mile delivery and also many online platforms grow to serve alternative customers. For a change that is happening as a result, the customer expectation is also increased, they expect shorter waiting time for deliveries, leading to many activities and job creation in the supply chain and driving the economy in terms of job creation and value creation.

E-commerce activity is happening to satisfy a new trend of customer's lifestyle. It can be seen from the growth of the sales and the amount of packaging which increases every year. In 2017, online retail sales in China reached 1.1 trillion U.S. Dollars which is the number of parcels over 40 billion orders and projects to reach 70 billion parcels in 2020 [1]. Thailand, at the same time, the volume of E-marketplace has increased from 74 million pieces in 2018 to 174 million pieces in 2019 (Tech Sauce, 2019). Moreover, from the situation of COVID-19 in 2020 leads the order volume of Ecommerce in February larger than in January 80\% [2].

The sales data of E-commerce's world trends is expected to continue to increase from 1.33 trillion US dollars in 2014 to 6.54 trillion US dollars in 2023. [3] Thailand 4.0 policy is introduced by the Thai government as a mega project to drive economic growth in the country. Therefore, the budget has been allocated to develop nationwide network leading to modern economic development through E-commerce. Logistics systems, reliability and quality of online shopping services are also improved then the shoppers feel confidence and convenience to shop via online. As a result, E-commerce in Thailand grows rapidly as same as the world's trend. The internet users in Thailand have been increased from 51 million users in 2019 to 52 million users in 2020 and an average internet usage was around 9 hours and 01 minutes per day [4], leading to Thailand is a number 1 in ASEAN B2C sales in Ecommerce. Thailand is a country that mixes an international and national E-commerce platform which provides more variety for shoppers when shopping. The value of the E-commerce trend in Thailand has been increased year on year. From 2017 to 2018, it was increased by $14.04 \%$ with the total value of 3.15 trillion Baht. [5]. To predict the E-commerce value in the next five years then data from 2015-2017 is used, the formula of E-commerce in Thailand is

$$
Y=291766 X-\left(7.66^{*}\left(10^{\wedge} 8\right)\right)
$$

When

$\mathrm{X}$ is Thai year

$\mathrm{Y}$ is the E-commerce value of that year (million Baht).

Therefore, E-commerce value in Thailand in 2021 is predicted to be 4.67 trillion Baht with $\mathrm{R}^{2}=0.9866$. The value of E-commerce in Thailand has been shown in Figure 2. 


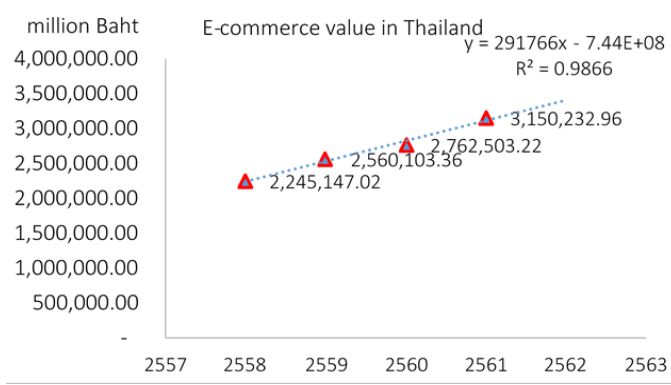

Fig.2. The value of E-commerce in Thailand [5]

\subsection{E-commerce process in Thailand}

In 2018, the value of E-Commerce for B2G (Business to Government) was 0.495 trillion Baht, B2C (Business to Customer) was 0.758 trillion Baht and B2B (Business to Business) was 1.5 trillion Baht which was the highest. However, according to the study the number orders placed for B2C models was the largest volume in Thailand.

The percentage of $\mathrm{B} 2 \mathrm{C}$ online that Thai shoppers have frequency to buy is Social Media $40 \%$ e.g., Facebook, Line, Instagram E-Marketplace 35\% e.g., Lazada, Shopee, JD Central and E-Tailer 25\% e.g., Homepro, Tesco Lotus, BigC [6].

The selling channels for B2C E-commerce model in Thailand can be divided into 3 types which are social media E-commerce, E-marketplace and E-tailer. Each E-commerce process is shown as below.

\subsubsection{Social media E-commerce process}

A social media E-commerce is the most popular Ecommerce in Thailand, which shares $40 \%$ of Ecommerce B2C model. The most famous social media platforms in Thailand are Line, Facebook and Instagram. The process of this model of E-commerce is the buyer can communicate directly through the seller then after the buyer designs to buy and transfer money to the seller, the seller sends the product to the buyer via $3^{\text {nd }} \mathrm{PL}$ provider. The process flow has been shown as Figure 3.

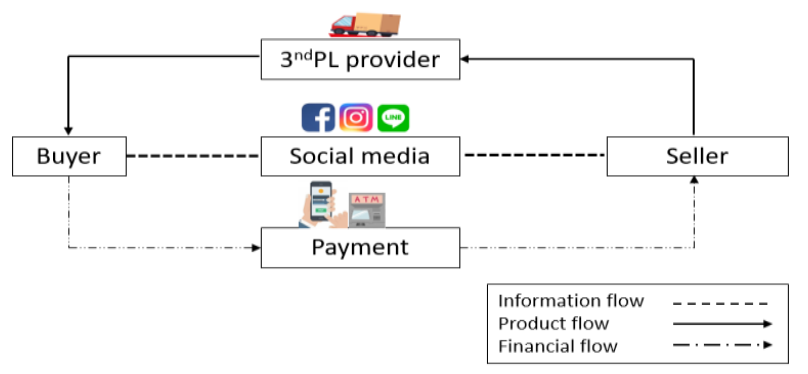

Fig.3. The process flow of Social media E-commerce

\subsubsection{E-marketplace process}

E-marketplace is one of $\mathrm{B} 2 \mathrm{C}$ E-commerce models. There are 2 main types of E-marketplace process which are the product has been stored at the seller's warehouse and stored at E-marketplace distribution center. The process of E-marketplace which stores the product at the seller's warehouse is that the buyer searches and places an order from E-marketplace platform such as Lazada, Shopee and JD Central, when the seller receives an order detail then the seller sends an order detail to the warehouse to pick and repack. After finishing preparing the product, the product status is then updated by the seller to inform the buyer that the product is ready to ship. After that E-Marketplace platform calls the Logistics provider to pick the product and then route the parcel, refer to postcode and dispatch to the customer's address. Flow process has been shown as Figure 4.

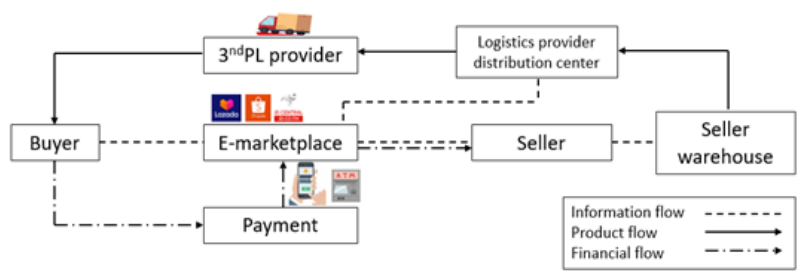

Fig.4. The process flow of E-marketplace 1

On the other hand, the process of E-marketplace which stores the product at E-marketplace distribution center, the seller sends the product from seller warehouse to Emarketplace distribution center. When the buyer searches and places an order, E-marketplace platform sends an information to the seller to update inventory and sends order details to E-marketplace distribution center to pick and repack and then dispatch the product to the customer's address. Flow process has been shown as Figure 5.

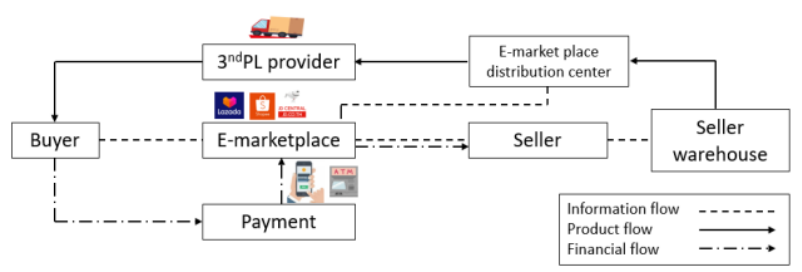

Fig. 5. The process flow of E-marketplace 2

\subsubsection{E-tailer process}

The E-tailer is another type of E-commerce B2C model in Thailand. The E-tailer looks like offline shopping but 
the buyer does not need to go to a retailer or store. When the buyer searches and places an order, an order detail is transferred to the E-tailer distribution center to pick and pack then dispatched the product to the customer's address. Flow process has been shown as Figure 6 .

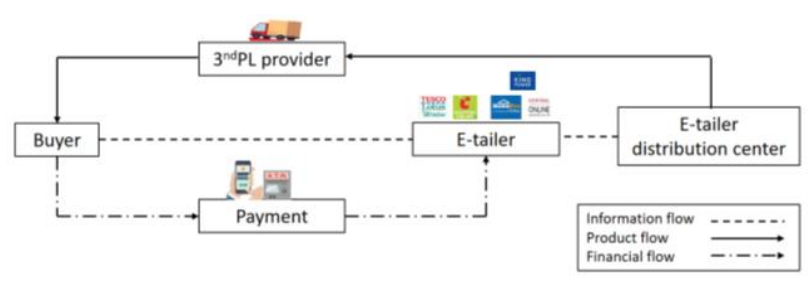

Fig.6. The process flow of E-tailer

The three types of E-commerce B2C model show different processes of how to buy and receive the product. It can be seen that the main activities of $\mathrm{B} 2 \mathrm{C}$ model are; search for the product, manage the order, pick, sort, repack and ship the product. These activities can be used to analyze the impaction of the environment.

\subsection{A study of e-commerce environmental impact in Thailand}

As the volume of E-commerce order is getting higher and the sales of E-commerce is increasing every year, therefore, E-commerce activities are the cause of environmental impact such as waste, pollution and congestion. The core competency of E-commerce is to deliver the product directly to the customer's address, then more vehicles are needed leading to traffic congestion. Then, pollution from engine combustion is produced as a result, it creates a carbon footprint on the distribution system. It is not only the shipping process of the last mile of E-commerce delivery that impacts the environment, but also the waste of packaging. The usage of hardware and devices or even information flow is also the energy consumed, heat released and carbon emitted. Therefore, the more demand for shopping experience increases, the higher environmental impact.

The waste in Thailand trends to rise every year, the record of Thailand's waste management information shows that the total waste can be divided into 3 groups which are proper waste disposal, renewable waste and improper waste disposal. In 2016, the record found that waste in Thailand was 27.06 million tons, which is projected to get higher year on year. As the order of Ecommerce has been increased it can be predicted that it may cause the increase of the waste in Thailand. Moreover, it can be seen that almost half of the total waste in Thailand is disposed improperly. Main Ecommerce waste is the packaging, which consists of 2 main material types which are paper and plastic such as cardboard boxes, order slip, bag, tape, cushion, strap and air bubble. Some kinds of waste can be recycled or generated renewable energy. Nevertheless, visible waste from E-commerce can be proper or improper waste depending on how well organized in management practice. If the waste is well managed by redesign, recycle or reuse then total waste would decrease, proper waste disposal and renewable waste would increase. Total waste in Thailand is shown in Figure 7.

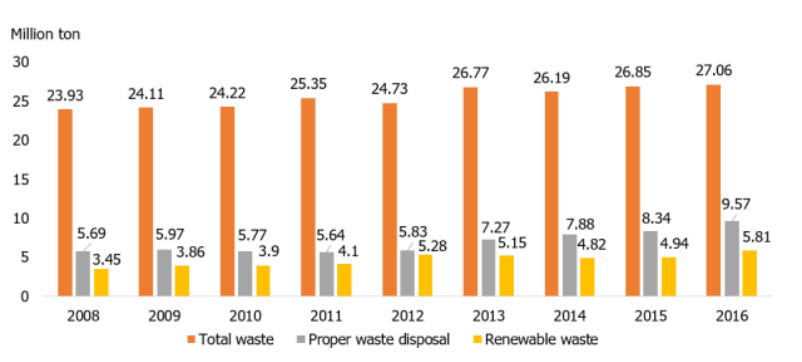

Fig.7. Total waste in Thailand

Recently, PM 2.5, the particle matter that has a diameter less than 2.5 micrometers is a new issue in Thailand. PM 2.5 is emitted during the combustion process [7]. These particles have an impact on health both in a short term and long term such as effect on the lung, nose and eyes as it is a very small particle of the mixture of solid particles and liquid droplets in the air [8]. Research in Thailand found that the main source of PM 2.5 comes from automobile emission and biomass burning [9]. At the same time, the product of Ecommerce has been delivered directly to customer's front doors, then the transportation activity is one of the main activities that may cause PM 2.5 from automobile emission from traffic sites.

\subsection{E-commerce environmental impact study in other countries}

Referring to an E-commerce environment impact study in other countries, a carbon footprint is used to calculate the emissions from the operations. It can be summarized the activities of E-commerce that impact the environment as packaging, transportation, energy consumption and information flow. The activities are calculated the carbon emission in terms of energy user (MJ), carbon emission $\left(\mathrm{CO}_{2} \mathrm{e}\right)$ and cost (monetary value). To evaluate carbon emission, many researches are done on comparison between online and offline shopping. At the same time, the review researches have also been done without the calculation but to create a new conceptual model or interview and questionnaire the related participant to conclude the task.

[10] Waste from packaging from online shopping is the point that must be concerned. The waste from 
packaging material includes paper bill, envelope, plastic bag, tape, bumping prevent and cardboard box. [11] There are 3 sources of carbon footprint in the process of E-commerce. 1. Transportation refers to fuel consumption values of all vehicles used in delivering product last mile. 2. Energy consumption refers to sources of energy used across the supply chain. 3 . Information flow refers to the electricity used to transmit information, estimation of emissions of printed labels necessary to trace the product through the supply chain.

[12] The study on carbon footprint from different customer behavior among traditional shopper (search, purchase and return in store), online shopper (search, purchase and return online) and online impatient shopper (search, purchase and return online with fast delivery) found that online shopping by normal online shopper has a lower environmental impact than the traditional shopper, beside when online impatient shopper who need to speed delivery trends to produce more carbon footprint than tradition shopper It is because the seller has to set special routes for last mile with speed delivery.

[13] Carbon emissions evaluation is calculated from product return, transportation, building and packaging. The calculation evaluation of carbon emissions comparison between conventional retail trade and Ecommerce in Shenzhen, China found that conventional retail trade has $\mathrm{CO}_{2}$ emissions higher than E-commerce. Even though conventional retail trade has higher environmental cost the $\mathrm{CO}_{2}$ emission, packaging from E-commerce activity is the main composition of carbon emission from E-commerce which is not found in the conventional retail trade.

[14] The main variable of impaction of carbon emission comparison in home delivery and trip to store is the number of drops per round. Two other factors are likely to have a great influence on the level of $\mathrm{CO}_{2}$ emissions, which are the chances of making a successful delivery at the first-time and the return process for unwanted/ damaged goods

[15] There are two large sources of emissions of online business which are last-mile delivery and packaging. Therefore, when selling multiple products via E-commerce for one transaction with no need to split shipments would reduce the average per item emissions by $30 \%$ and cut shipping costs more than $50 \%$. Furthermore, the separate shipped order means increased packaging leads to produce more carbon footprint and stress to the environment. The factors that bring the carbon footprint of E-commerce over traditional is delivery speed and frequency of delivery order. It is because the faster customer needs the product, the more schedules and the more route splitting to serve customer need, it also leads to the more packagings have been produced.

\subsection{An analysis of e-commerce process and activities on the environmental impact in Thailand}

Refer to E-commerce environmental impact study in other countries, it can be evaluated the activities of Ecommerce that impact the environment by using the value of carbon footprint. Activities in the supply chain have both direct and indirect impacts on the environment. To measure the environmental impact of each process throughout the supply chain, it can be measured in 5 areas which are carbon emission, air pollution, liquid waste, general waste and \% recycled waste. The carbon footprint sources in the process of E-commerce are packaging, transportation, energy consumption and information flow. Therefore, it can be summarized Ecommerce processes and activities divided by supply chain partner as table below;

Table 1. An E-commerce process and activities on the environmental impact in Thailand

\begin{tabular}{|c|l|c|}
\hline $\begin{array}{c}\text { Process } \\
\text { category }\end{array}$ & \multicolumn{1}{|c|}{ Activity } & Remark \\
\hline \multirow{2}{*}{$\begin{array}{c}\text { Customer } \\
(\mathrm{CC})\end{array}$} & $\begin{array}{l}\text { Search, Make an order, } \\
\text { Make a payment, Track an } \\
\text { order, Review }\end{array}$ & $\mathrm{CC} 1$ \\
\cline { 2 - 3 } & Return & $\mathrm{CC} 2$ \\
\hline Seller (CS) & $\begin{array}{l}\text { Add product, Adjust stock, } \\
\text { Collect an order }\end{array}$ & $\mathrm{CS}$ \\
\hline $\begin{array}{c}\text { E-commerce } \\
\text { marketplace } \\
(\mathrm{CM})\end{array}$ & $\begin{array}{l}\text { Run website and application, } \\
\text { Pass through an order }\end{array}$ & $\mathrm{CM}$ \\
\hline $\begin{array}{c}\text { Distribution } \\
\text { center (CD) }\end{array}$ & Store, Pick, Sort, Repack & CD1 \\
\cline { 2 - 3 } & Packaging & CD2 \\
\hline $\begin{array}{c}\text { Delivery agent } \\
(\mathrm{CA})\end{array}$ & Route & CA1 \\
\cline { 2 - 3 } & Collect, Deliver \\
\hline
\end{tabular}

From Table 1 show the activities of E-commerce of each process category then it can be described how it makes an impact on an environment. A total carbon footprint $\left(\mathrm{kgCO}_{2} \mathrm{e}\right)$ of E-commerce activities in Thailand (CE) has been shown as formula below;

$$
C E=C C+C S+C M+C D+C A
$$

When

$\mathrm{CE}=$ Total carbon footprint of E-commerce activities in Thailand.

$\mathrm{CC}=$ Carbon footprint from customer's activities. 
$\mathrm{CS}=$ Carbon footprint from seller's activities.

$\mathrm{CM}=$ Carbon footprint from E-commerce marketplace's activities.

$\mathrm{CD}=$ Carbon footprint from distribution center's activities.

$\mathrm{CA}=$ Carbon footprint from delivery agent's activities.

Carbon footprint of customer's activities (CC) has been shown as formula below,

$$
\begin{gathered}
C C=C C 1+C C 2 \\
C C 1=E U_{C C 1} \times E F_{E U} \\
C C 2=E U_{C C 2} \times E F_{E U}+F C_{C C 2} \times E F_{F C}
\end{gathered}
$$

When

$\mathrm{CC} 1=$ carbon footprint from activities of search for product detail, make an order, make a payment, track an order and review.

CC2 = carbon footprint from activities of return.

$\mathrm{EU}_{\mathrm{CC} 1}=$ Electricity usage $(\mathrm{kwh})$ from charging device from activity of search for product detail, make an order, make a payment, track an order and review.

$\mathrm{EF}_{\mathrm{EU}}=$ Value of emission factor of Electricity (0.5986) (kgCO2e/kWh) source: Thai National LCI database, TIIS-MTEC-NSTDA (with TGO electricity 2016-2018).

$\mathrm{EU}_{\mathrm{CC} 2}=$ Electricity usage $(\mathrm{kwh})$ from charging device when using the device to making a ticket in the system of returning.

$\mathrm{FC}_{\mathrm{CC} 2}=$ Fuel consumption (1) from transportation to return a physical product to the seller.

$\mathrm{EF}_{\mathrm{FC}}=$ Value of emission factor of diesel oil (2.7446) (kgCO2e/l) source: IPCC Vol.2 table 3.2.1, 3.2.2 PTT.

Carbon footprint of seller's activities (CS) has been shown as formula below,

$$
C S=E U_{C S} x E F_{E U}
$$

When

$E U_{C S}=$ Electricity usage (kwh) from using equipment ex. computer to add new product, adjust stock, collect an order.

Carbon footprint of E-commerce marketplace's activities (CM) has been shown as formula below,

$$
C M=E U_{C M} x E F_{E U}
$$

When

$\mathrm{EU}_{\mathrm{CM}}=$ Electricity usage (kwh) from using equipment ex. computer to running websites and applications and passing through an order.

Carbon footprint of distribution center's activities (CD) has been shown as formula below,

$$
C D=C D 1+C D 2
$$

$$
C D 1=E U_{C D 1} x E F_{E U}
$$

$$
C D 2=\sum_{i=1}^{n}\left(P G_{C D 2 i} x E F_{P G i}\right)
$$

When

CD1 = carbon footprint from activities of store, pick, sort and repack.

$\mathrm{CD} 2$ = carbon footprint from packaging.

$\mathrm{EU}_{\mathrm{CD} 1}=$ Electricity usage $(\mathrm{kwh})$ from using equipment such as forklift, sorter, conveyor to move the product.

$\mathrm{PG}_{\mathrm{CD} 2}=$ Packaging $\mathrm{i}$ (unit) that is used to protect the product and identify customer's address such as cardboard parcel, paper bill, plastic bag, tape, bumping prevent and customer's address printed sticker.

$\mathrm{EF}_{\mathrm{PG}}=$ Value of emission factor of packaging i, e.g., cardboard box (1.8679) (kgCO2e/unit), paper (1.6184) (kgCO2e/unit) source: Thai National LCI database, TIIS-MTEC- NSTDA, LLDPE (2.6258) (kgCO2e/unit) source: Thai National LCI database, TIIS-MTEC- 
NSTDA (with TGO electricity 2016-2018), Sticker (0.5100) (kgCO2e/unit) source: Environment 2.0, IPCC 2007 GWP 100 a.

Carbon footprint of delivery agent's activities (CA) has been shown as formula below,

$$
\begin{gathered}
C A=C A 1+C A 2 \\
C A 1=E U_{C A 1} x E F_{E U} \\
C A 2=F C_{C A 2} \times E F_{F C}
\end{gathered}
$$

When

$\mathrm{CA} 1=$ carbon footprint from activities of routing.

CA2 = carbon footprint from activities of collecting and delivering.

$\mathrm{EU}_{\mathrm{CA} 1}=$ Electricity usage $(\mathrm{kwh})$ from using equipment ex. computer to running software to sort and route an order by customer's address.

$\mathrm{FC}_{\mathrm{CA} 2}=$ Fuel consumption (1) from transportation to collect the production from the station and dispatch the product to customer's address.

\section{Conclusion}

E-commerce sales projects increase every year and make a bigger share from global commercials. It is because E-commerce makes life easier, helps both seller and buyer to access from anywhere and customers can receive products directly to customer's address. Ecommerce also creates sustainability in terms of driving economic and job creation. The value of E-commerce in Thailand is predicted to be 4.67 trillion Baht in 2021 by using the data from $2015-2017$ as the formula $\mathrm{Y}=$ $291766 \mathrm{X}-\left(7.66^{*}\left(10^{\wedge} 8\right)\right)$. The result of doing Ecommerce is to generate waste, congestion and pollution. The study found that waste in Thailand has increased, in 2016 waste in Thailand was 27.06 million tons and found that PM2.5 and pollution come from automobile emission due to last mile delivery activity. There are 3 types of E-commerce B2C model which are social media E-commerce, E-marketplace and E-tailer, then the study finds out the E-commerce activities that make impact to environment from E-commerce partner which are firstly, customer: search, make an order, make a payment, track an order, receive, review and return. Secondly, seller: add product, adjust stock and collect an order detail. Thirdly, E-commerce marketplace: run website or application and pass through an order detail. Fourthly, warehouse: store, pick, sort and repack and finally, delivery agent: collect, route and deliver.

Most of the researchers that study on Environmental impact when doing E-commerce have been done on calculating the carbon footprint of the transport process. On the other hand, information flow and the distribution center process are less concerned. At the same time, the different component between online shopping and offline shopping is packaging as it can be seen that when buying products via E-commerce the products have to be protected by using packaging and protective stuff so packaging is another concern when calculating the carbon emission of E-commerce activities. The next step is to investigate and evaluate in depth of each process of E-commerce activities that produce carbon in the context of Thailand.

\section{References}

1. H. Duana, G. Songa, S. Qub, X. Dongc, M. Xub, (2019). Post-consumer packaging waste from express delivery in China. Resources, Conservation \& Recycling 144 137-143.

2. W. Puttanont, (2020). The Bangkok insight. Online. https:/www.thebangkokinsight.com/311684/ Pollution Control Department. (2017). Pollution Report 2016. Pollutio Control Department.

3. Statista. (2019). E Commerce Thailand. Digital Market Outlook. Online. https://www.statista.com/outlook/243/126/ecomme rce/thailand.

4. My-thai.org. (2020). Digital Thailand 2020. Online. https://my-thai.org/digital-thailand-2020/.

5. ETDA annual report. (2019). The Digital Transformation is a Marathon Journey. Electronic Transaction Development Agency. Miniistry of Digital Economy and ociety. ISBN. 978-616-795649-7.

6. Tech Sauce. (2019.) Social E-Commerce. Online. https://techsauce.co/news/priceza-e-commerce2020-trends.

7. Defra.gov.uk. (2019). Sources and Effects of PM2.5. Deaprtment for Environmnet Food \& Rural Affairs Public Health. Online. https://laqm.defra.gov.uk/public-health/pm25.html.

8. Health.ny.gov. (2018). Questions and Answers. Department of Health: Fine Particle (PM 2.5). Online.

https://www.health.ny.gov/environmental/indoors/ air/pmq_a.htm 
9. N. Chuersuwan, N. Subuntith, L. Sukanda, K.Tida, (2008). Levels and major sources of PM2.5 and PM10 in Bangkok Metropolitan Region. Environment International 34, 5.

10. K. Chueamuangphan, P. Kashyap, C. Visvanathan, (2020). Packaging Waste from E-Commerce: Consumers' Awareness and Concern. In: Ghosh S. (eds) Sustainable Waste Management: Policies and Case Studies. 27-41. Online. https://link.springer.com/chapter/10.1007/978981-13-7071-7_3.

11. M. Zhang, Y. Chen, Y. Shen, (2016). China's Environmental Threats of Internet Shopping Packaging Wastes. Environmental \& Analytical Toxicology. 6, 5 .

12. D. Weideli, (2013). Environmental analysis of US online shopping. Master Thesis for MIT Center for Transportation \& Logistics, Cambridge MA, U.S.A.

13. Y.B. Zhao, G.Z. Wu, Y.X. Gong, M.Z. Yang, H.G. Ni (2018) Environmental benefits of electronic commerce over the conventional retail trade? A case study in Shenzhen, China. Science of The Total Environment. 679 378-386.

14. A. Mckinnon, S. Cullinane, (2010). Comparative analysis of the carbon footprints of conventional and online retailing: A "last mile" perspective. International Journal of Physical Distribution \& Logistics Management.

15. A. Cheris, C. Taylor, J. Hayes, J. Davis-Peccoud, (2017). Retailers' Challenge: How to Cut Carbon Emissions as E-Commerce Soars. https://www.bain.com/insights/how-to-cut-carbonemissions-as-ecommerce-soars/ 